\title{
Low dose of interferon- $\alpha$ improves the clinical outcomes of docetaxel in patients with castration-resistant prostate cancer: A pilot study
}

\author{
YUN-FEI LI ${ }^{1,2,3 *}$, QIN-ZHANG WANG ${ }^{2 *}$, TAO-TAO ZHANG ${ }^{2,3}$, LEI LI ${ }^{1}$, JIANG-PING WANG $^{2}$, \\ GUO-FU DING ${ }^{2}$ and DA-LIN HE ${ }^{1}$ \\ ${ }^{1}$ Department of Urology, First Hospital of Xi'an Jiaotong University, Xi'an, Shaanxi 710061; \\ ${ }^{2}$ Department of Urology, First Hospital of Shihezi University, Shihezi, Xinjiang 832008; \\ ${ }^{3}$ Department of Urology, Renmin Hospital, Hubei University of Medicine, Shiyan, Hubei 442000, P.R. China
}

Received April 6, 2013; Accepted October 21, 2013

DOI: $10.3892 / 01.2013 .1653$

\begin{abstract}
The aim of this study was to test whether a low dose of interferon- $\alpha-2 b$ (IFN- $\alpha 2 b)$ enhances the clinical outcome of docetaxel (DXT) in patients with castration-resistant prostate cancer (CRPC). A prospective controlled trial of 40 CRPC patients receiving $5 \mathrm{mg}$ of prednisone twice daily was conducted, where patients were randomly assigned to be administered $75 \mathrm{mg} / \mathrm{m}^{2}$ DXT plus $3 \mathrm{mIU} / \mathrm{m}^{2}$ IFN- $\alpha 2 \mathrm{~b}$ (group $\mathrm{A}, \mathrm{n}=20$ ) or $75 \mathrm{mg} / \mathrm{m}^{2}$ DXT alone (group $\mathrm{B}, \mathrm{n}=20$ ). The prostate-specific antigen (PSA) response, tumor response, progression-free survival (PFS) and overall survival (OS) were evaluated. There was no statistically significant difference in PSA response rate between groups A and B (65 vs. 47.4\%, $\mathrm{P}=0.341)$. The tumor response rate in group A was significantly greater compared with that in group B (55 vs. $21.1 \%$, $\mathrm{P}=0.048$ ). The median PFS was longer in group A compared with that in group B (10 vs. 8 months, $\mathrm{P}=0.043)$. There was no statistically significant difference in median OS between the two groups ( 19 vs. 17 months, $\mathrm{P}=0.348$ ), but one patient displayed a complete tumor response in group A. In groups A and $\mathrm{B}$, transient grade 3 to 4 neutropenia was observed in nine and six patients, grade 3 to 4 anemia was observed in three and five patients, and grade 3 to 4 general fatigue was observed in four and one patient(s), respectively. The proportion of patients with grade 3 to 4 toxicity was not statistically different between the two groups. A low dosage of IFN- $\alpha 2 b$
\end{abstract}

Correspondence to: Dr Da-Lin He, Department of Urology, First Hospital of Xi'an Jiaotong University, 76 Yantan West Road, Xi'an, Shanxi 710061, P.R. China

E-mail: urologist02@yahoo.cn

*Contributed equally

Key words: castration-resistant prostate cancer, docetaxel, interferon- $\alpha-2 b$ may improve the antitumor activity of DXT with an acceptable toxicity profile in patients with CRPC.

\section{Introduction}

Early-stage prostate cancer can be cured by radical surgery or radiation therapy. However, $\sim 10-20 \%$ of men with prostate cancer have metastatic disease, and many others develop metastases despite primary treatment $(1,2)$. Although the majority of patients with advanced metastatic disease initially respond to conventional androgen deprivation with medical or surgical castration, the response to hormonal treatment lasts for a median duration of 18-24 months. Thus, most patients eventually become resistant to therapy and develop hormone refractory prostate cancer, also known as castration-resistant prostate cancer (CRPC) (2).

Treatment of CRPC is currently a challenge. Options for improved survival in patients with CRPC are limited, but docetaxel (DXT) chemotherapy is the clearly established treatment (3). While DTX chemotherapy has shown success with overall survival improved by 2.5 months compared with that of mitoxantrone-based therapy, only $\sim 48 \%$ of patients respond, and drug resistance rapidly develops to treatment with a combination of DXT and prednisone $(4,5)$. Two important mechanisms of tumor resistance, which may be exploited therapeutically, are the overexpression of $\mathrm{Bcl}-2$ and the loss of p53 function, both of which contribute to the resistance of CRPC to DXT (5-10).

It has been demonstrated that interferon- $\alpha-2 b$ (IFN- $\alpha 2 b)$ decreases the expression of Bcl-2 and increases the expression of p53 $(11,12)$. Similarly, IFN- $\alpha 2 b$ has been shown to promote the effects of DTX chemotherapy in vitro (13). A low dosage of IFN- $\alpha 2 b$ showed antitumor activity in prostate cancer patients in a recent study with a follow-up period of $>10$ years (14). In addition, IFN- $\alpha 2 b$ alone or in combination with chemotherapy drugs has been proven safe and effective in various metastatic malignant tumors $(15,16)$. However, though a high dosage of IFN- $\alpha 2 b$ alone demonstrates antitumor activity, its toxicity is intolerable for use in CRPC (17). Conversely, toxicity levels with a moderate 
dosage of IFN- $\alpha 2 b$ alone are acceptable, whereas the efficacy is limited (18).

These facts led us to hypothesize that IFN- $\alpha 2 \mathrm{~b}$ may be able to expand the effects of DXT chemotherapy. In this pilot study, we conducted a prospective analysis to evaluate the efficacy and toxicity of this regimen in patients with CRPC.

\section{Patients and methods}

Patients. From January 2007 to September 2009, 40 patients from the Department of Urology, First Hospital of Shihezi University (Shihezi, China) with CRPC were enrolled in this study. To be eligible for this study, patients had to have an Eastern Cooperative Oncology Group (ECOG) performance status of 0 or 1 (http://ecog.dfci.harvard.edu/general/perf_stat. html), and evidence of progressive metastatic disease despite androgen deprivation therapy. Patients were required to have a serum testosterone concentration of $<50 \mathrm{ng} / \mathrm{dl}$ and prior treatment with maximum androgen blockade with evidence of treatment failure. Patients were required to have a measurable soft tissue lesion. Patients had to have adequate function of bone marrow, liver, heart, kidney and lung, defined as white blood cell count $\geq 4,000 / \mathrm{mm}^{3}$, granulocytes $\geq 2,000 / \mathrm{mm}^{3}$, platelet count $\geq 100,000 / \mathrm{mm}^{3}$, bilirubin $\leq 1.5 \mathrm{mg} / \mathrm{dl}$, alanine aminotransferase and aspartate aminotransferase $\leq 2$-fold the institutional upper limit of normal, creatinine $\leq 2.0 \mathrm{mg} / \mathrm{dl}$ or a calculated creatinine clearance $\geq 50 \mathrm{ml} / \mathrm{min}$, left ventricular ejection fraction $\geq 50 \%$ as demonstrated by echocardiography, and forced expiratory volume in one second/forced vital capacity $\geq 70 \%$. Patients were required to have no history of myocardial infarction within 6 months of study entry, and no history of deep venous thrombosis.

The study was performed after approval by the Human Investigations Committee of the Medical College of Shihezi University (Shihezi, China). Informed consent was obtained from each patient.

Medical protocol. Throughout the treatment period, patients in group A received DXT $\left(75 \mathrm{mg} / \mathrm{m}^{2}\right)$ by intravenous administration over $60 \mathrm{~min}$ on day $1, \mathrm{IFN}-\alpha 2 \mathrm{~b}\left(3 \mathrm{mIU} / \mathrm{m}^{2}\right)$ was subcutaneously injected on days 16,18 and 20; and oral prednisolone $(5 \mathrm{mg}$ ) was administered twice daily on days 1 to 21 , on each 21 day cycle. Patients in group B were treated as abovementioned, but were not administered IFN- $\alpha 2 b$. For the first cycle of treatment, all patients were hospitalized for 8-10 days to check renal and liver functions and to observe adverse events. For the second course of treatment, all patients were treated on an outpatient basis. The treatment was continued until the disease progressed or unacceptable adverse events occurred. Patients were hospitalized if grade 3 to 4 neutropenia was observed, and granulocyte-colony stimulating factor (G-CSF) was used. The dose of DXT was reduced by $10 \mathrm{mg} / \mathrm{m}^{2}$ in subsequent treatment cycles if granulocytes remained at $\leq 2,000 / \mathrm{mm}^{3}$ after the G-CSF treatment in patients with grade 3 to 4 neutropenia.

Treatment evaluation. The endpoints of this study comprised prostate-specific antigen (PSA) response, tumor response, the time to PSA progression, and toxicity. PSA response was defined as a reduction of at least $50 \%$ in the baseline levels for
4 weeks. PSA progression was defined as a rise in PSA levels exceeding $25 \%$ of the baseline level. The tumor response was documented using radiographs according to response evaluation criteria in solid tumors (RECIST) (19) after four cycles of therapy (performed by a single radiologist). Tumor complete response was defined as the disappearance of all evidence of a tumor and all symptoms of cancer for at least 12 weeks. Partial response was defined as $\geq 50 \%$ decrease in the sum of the products of diameters of all measured lesions persisting for at least 12 weeks. Tumor progression was defined as a rise in the diameter exceeding $25 \%$ of the baseline level. Progression-free survival (PFS) was defined from the date of the first chemotherapy treatment to the first occurrence of PSA and tumor progression. Overall survival (OS) was defined from the date of the first chemotherapy treatment to the date of death from any cause. The Cancer Institute Common Toxicity Criteria, version 4.0 was used to evaluate patients for toxicity (http:// ctep.cancer.gov/protocolDevelopment/electronic_applications/ctc.htm).

Statistical analysis. Descriptive statistics were used to characterize patients at study entry. Patient age and the number of cycles of treatment undergone were compared using the Mann-Whitney U test. Other patient demographics, response rates and toxicity rates were compared using Fisher's exact test. The Kaplan-Meier method was used to characterize the PFS in terms of PSA response. $\mathrm{P}<0.05$ was considered to indicate a statistically significant difference (two-sided).

\section{Results}

Patient characteristics. Patient characteristics are summarized in Table I. Baseline clinicopathological characteristics were generally well-balanced between the two groups and no significant difference between the two groups was observed.

Efficacy. The treatment and efficacy are listed in Table II. One of the 20 patients in group B discontinued treatment by choice and was admitted to a hospice during the second week of the study. The most frequent reason for stopping treatment was disease progression. The PSA response rates were $65 \%$ in group A and $47.4 \%$ in group B among evaluated patients, and there was no statistically significant difference between the two groups $(\mathrm{P}=0.341)$.

In group $\mathrm{A}$, among all the 20 patients with measurable lesions, 55\% (11/20) achieved a tumor response according to the RECIST criteria. The patients with tumor response included seven for lymph node lesions, two for liver lesions and two for lung lesions. Notably, one patient displayed a complete response in group A (Fig. 1). This patient was a 58-year-old male with biopsy-proven retroperitoneal lymph node involvement (Fig. 1A-C). Six months after DTX plus IFN- $\alpha 2$ b treatment, the PSA level had decreased from $755 \mathrm{ng} / \mathrm{ml}$ to an undetectable level and the retroperitoneal lymph node mass had disappeared (Fig. 1D-F). In group B, among all the 19 cases, 21.1\% (4/19) of patients achieved a partial response. These responses were observed lymphnode and liver lesions (two patients) and lung lesions (two patients). However, no patients achieved a complete response in group B. The objective tumor response rates were $55 \%$ in group $\mathrm{A}$ and $21.1 \%$ in group B among evaluated patients, 
Table I. Patient characteristics.

\begin{tabular}{|c|c|c|c|}
\hline Index & Group $A, n=20$ & Group $B, n=20$ & P-value \\
\hline \multicolumn{4}{|l|}{ Age (years) } \\
\hline Median (range) & $68(58-77)$ & $66(62-76)$ & 0.642 \\
\hline \multicolumn{4}{|l|}{ ECOG performance score, n (\%) } \\
\hline 0 & $11(55)$ & 7 & 0.341 \\
\hline 1 & $9(45)$ & 13 & 0.200 \\
\hline \multicolumn{4}{|l|}{ Prior treatment, n (\%) } \\
\hline Prostatectomy + hormonal therapy & $5(25)$ & $7(35)$ & 0.501 \\
\hline Radiotherapy + hormonal therapy & $13(65)$ & $11(55)$ & 0.748 \\
\hline Hormonal therapy & $2(10)$ & $2(10)$ & 1.000 \\
\hline \multicolumn{4}{|l|}{ Site of metastasis, n (\%) } \\
\hline Bone & $18(90)$ & $19(95)$ & 0.501 \\
\hline Lymph node & $10(50)$ & $8(40)$ & 0.748 \\
\hline Liver & $3(10)$ & $2(10)$ & 0.695 \\
\hline Lung & $6(30)$ & $8(40)$ & 1.000 \\
\hline \multicolumn{4}{|l|}{ PSA } \\
\hline Median (range) & $49.05(10.84-1328.53)$ & $63.27(12.20-1324.48)$ & 0.317 \\
\hline \multicolumn{4}{|l|}{ Biopsy Gleason score, n (\%) } \\
\hline$\leq 6$ & $8(40)$ & $10(50)$ & 0.751 \\
\hline 7 & $6(30)$ & $3(15)$ & 0.451 \\
\hline $8-10$ & $6(30)$ & $7(35)$ & 1.000 \\
\hline \multicolumn{4}{|c|}{ Time from start of ADT to CRPC (months) } \\
\hline Median (range) & $17.50(7.45-67.16)$ & $15.00(6.68-50.43)$ & 0.131 \\
\hline
\end{tabular}

Group A, $75 \mathrm{mg} / \mathrm{m}^{2}$ DXT plus $3 \mathrm{mIU} / \mathrm{m}^{2}$ IFN- $\alpha 2 \mathrm{~b}$; group B, $75 \mathrm{mg} / \mathrm{m}^{2}$ DXT alone; ECOG, Eastern Cooperative Oncology Group; PSA, prostat-specific antigen; ADT, androgen deprivation therapy; CRPC, castration-resistant prostate cancer.

Table II. Treatment and efficacy.

\begin{tabular}{lcccc}
\hline Index & Group A & Group B & P-value \\
\hline $\begin{array}{l}\text { No. of cycles (months) } \\
\quad \text { Median (range) }\end{array}$ & $8(3-12)$ & 9 & $(2-12)$ & 0.573 \\
Dose reduction (\%) & $15(3 / 20)$ & $10.5(2 / 19)$ & 1.000 \\
PSA response (\%) & $65(13 / 20)$ & $47.4(9 / 19)$ & 0.341 \\
Objective tumor response & $55(11 / 20)$ & $21.1(4 / 19)$ & 0.048 \\
PFS (months) & & & & \\
$\quad$ Median (range) & $10(2-24)$ & 8 & $(2-22)$ & 0.043 \\
Overall survival (months) & & & & \\
$\quad$ Median (range) & $19(7-19)$ & 17 & $(8-23)$ & 0.348 \\
\hline
\end{tabular}

Group A, $75 \mathrm{mg} / \mathrm{m}^{2}$ DXT plus $3 \mathrm{mIU} / \mathrm{m}^{2} \mathrm{IFN}-\alpha 2 \mathrm{~b}$; group B, $75 \mathrm{mg} /$ $\mathrm{m}^{2}$ DXT alone; PSA, prostate-specific antigen; PFS, progression-free survival.

demonstrating a statistically significant difference between the two groups $(\mathrm{P}=0.048)$.

Fig. 2A shows PFS by treatment group. The median PFS was 10 months (range 2-24; 95\% CI, 5.98-14.02) for group A and 8 months (range 2-22; 95\% CI, 5.94-10.06) for group B, with a $44 \pm 11$ and $22 \pm 10 \%$ PFS rate at 1 year in the two groups, respectively. There was a statistically significant difference in PFS in groups A and $\mathrm{B}(\mathrm{P}=0.043)$.

Fig. 2B shows the OS by treatment group. Median OS was 19 months (range 7-19; 95\% CI, 17.64-20.37) for group A and 17 months (range 8-23; 95\% CI, 14.33-19.67) for group B, with an overall survival rate of $45 \pm 12$ and $28 \pm 11 \%$ at 2 years, respectively. There was no statistically significant difference in OS by treatment in the two groups $(\mathrm{P}=0.348)$.

Toxicity. Table III shows the hematological and non-hematological toxicities stratified by grade and treatment group. In groups A and B, transient grade 3 to 4 neutropenia occurred in nine and six patients, grade 3 to 4 anemia occurred in three and five patients, and grade 3 to 4 general fatigue was observed in four and one patient(s), respectively. The proportion of patients with grade 3 to 4 toxicity displayed no statistically significant difference between the two groups $(\mathrm{P}>0.05)$.

\section{Discussion}

The present study demonstrated that the tumor response rates in group A were significantly greater than those in group B. This difference may be due to the activity of IFN- $\alpha 2 b$ against 

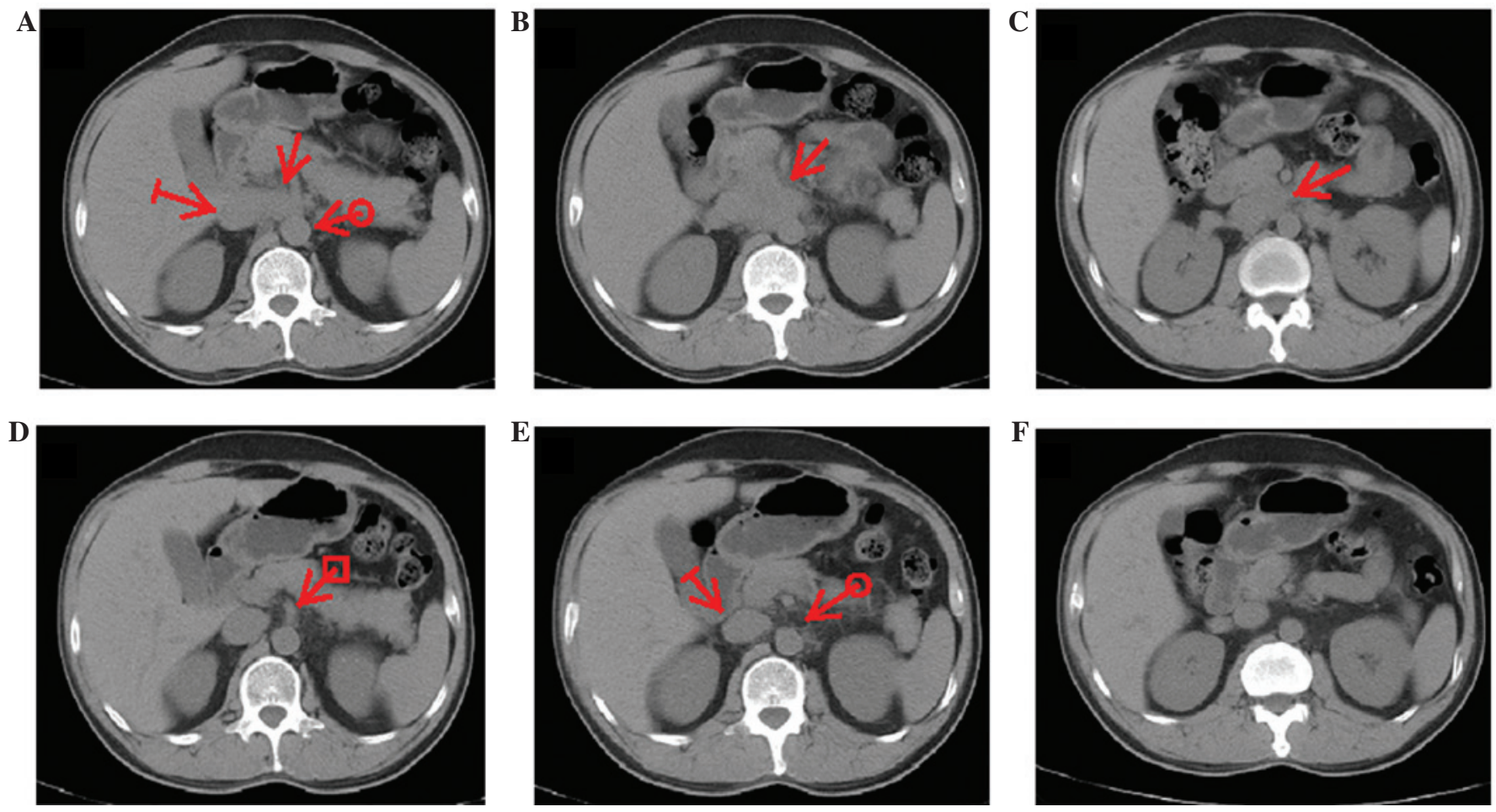

Figure 1. Following administration of docetaxel plus interferon- $\alpha$ for 6 months, a metastatic retroperitoneal lymph node tumor disappeared in the computed tomography scans of a 58-year-old male. (A-C) Pre-treatment image of retroperitoneal lymph node tumor $(6 \mathrm{~cm}$ in diameter) located between the aorta and vena cava. The boundaries of the tumor and the vena cava are unclear (arrow, metastatic retroperitoneal lymph node; flat-shaped arrow, vena cava; circular arrow, aorta). (D-F) Post-treatment image demonstrates the disappearance of metastatic mass. The vena cava and aorta boundaries are clearly defined (square arrow, superior mesenteric artery).

A

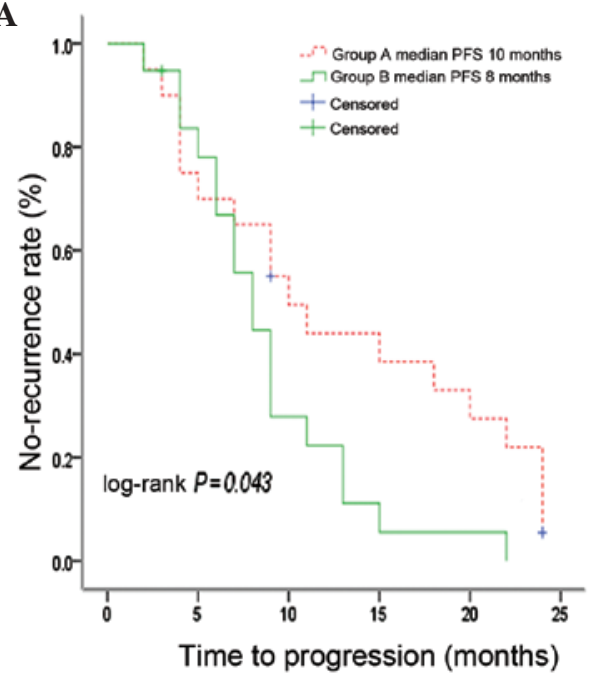

B

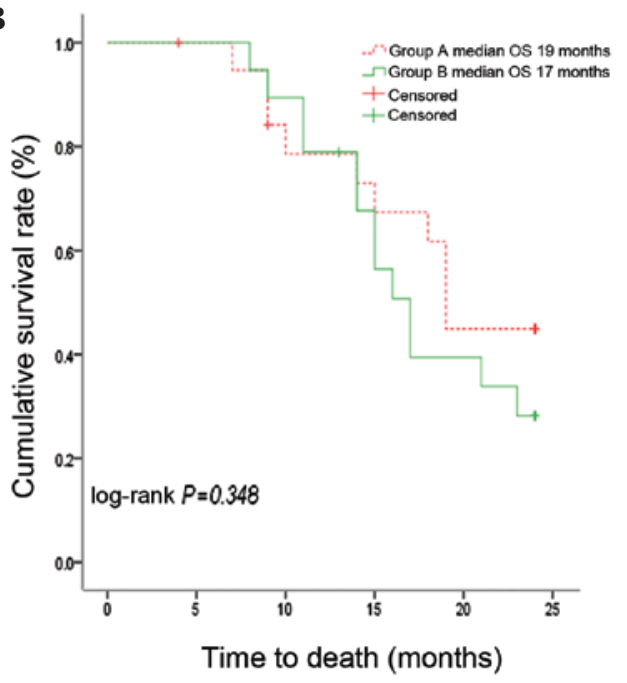

Figure 2. Kaplan-Meier estimate of (A) progression-free survival and (B) overall survival. PFS, progression-free survival; OS, overall survival; Group A, $75 \mathrm{mg} / \mathrm{m}^{2}$ DXT plus $3 \mathrm{mIU} / \mathrm{m}^{2}$ IFN- $\alpha 2 \mathrm{~b}$; group B, $75 \mathrm{mg} / \mathrm{m}^{2}$ DXT alone; censored, (A) PSA progression did not occur in follow-up period; censored (B), patients were alive in the follow-up period.

CRPC. However, the rates of PAS and tumor response were 65 and $55 \%$, respectively, which were higher than those observed in the study by DiPaola et al (23 and 15\%, respectively) (20). We hypothesize that this difference between the trial by DiPaola et $\mathrm{al}$ and the present study was due to the following reasons: firstly, the DXT regimen was different, as DiPaola et al used DXT combined with IFN- $\alpha 2 b$ and 13-cis retinoic acid. We administered DXT combined with prednisone and
IFN- $\alpha 2 b$. DXT with prednisone has better efficacy and less toxicity, as has been confirmed by two large phase III clinical trials (PSA and tumor response rates were 44.4 and $44.2 \%$, respectively) $(3,4)$. Another reason is the difference in patient characteristics, particularly the metastatic sites. The present study had more patients with lymph node lesions than the study by DiPaola et al. A higher response of the lymph node lesions was also found in the study by van Haelst-Pisani et al (17); 
Table III. Treatment-related toxicity.

\begin{tabular}{|c|c|c|c|c|c|}
\hline \multirow[b]{2}{*}{ Toxicity } & \multicolumn{2}{|c|}{ Group $A, n=20$} & \multicolumn{2}{|c|}{ Group B, n=19 } & \multirow[b]{2}{*}{ P-value (grade 3-4) } \\
\hline & Grade 1-2 & Grade 3-4 & Grade 1-2 & Grade 3-4 & \\
\hline Neutropenia, n (\%) & $7(35)$ & $9(45)$ & $8(40)$ & $6(30)$ & 0.514 \\
\hline Anemia & $7(35)$ & $3(15)$ & $8(40)$ & $5(25)$ & 0.451 \\
\hline Febrile neutropenia & $3(15)$ & 0 & $5(25)$ & 0 & \\
\hline Platelets & $2(10)$ & 0 & 0 & 0 & \\
\hline Fever & $3(15)$ & 0 & $3(15)$ & 0 & \\
\hline Chills & $2(10)$ & 0 & $4(20)$ & 0 & \\
\hline Allergic reaction & 0 & 0 & $1(5)$ & 0 & \\
\hline Nausea/vomiting & $2(10)$ & 0 & $3(15)$ & 0 & \\
\hline Diarrhea & $4(20)$ & 0 & $2(10)$ & 0 & \\
\hline General fatigue & $1(5)$ & $4(20)$ & $2(10)$ & $1(5)$ & 0.342 \\
\hline Edema & $2(10)$ & 0 & $3(15)$ & 0 & \\
\hline Liver dysfunction & $2(10)$ & 0 & $4(20)$ & 0 & \\
\hline
\end{tabular}

Group A, $75 \mathrm{mg} / \mathrm{m}^{2}$ DXT plus $3 \mathrm{mIU} / \mathrm{m}^{2} \mathrm{IFN}-\alpha 2 \mathrm{~b}$; group B, $75 \mathrm{mg} / \mathrm{m}^{2} \mathrm{DXT}$ alone.

however, in this study, IFN- $\alpha 2 b$ was not combined with DXT and IFN- $\alpha 2 b$ toxicity is intolerable for patients administered high-dose IFN- $\alpha 2 b$ alone (10 mIU). In particular, one patient with a metastatic retroperitoneal lymph node $(6 \mathrm{~cm})$ achieved a complete tumor response in group A. In this patient, an undetectable PSA level and complete regression of disease persisted for more than 18 months. Complete disease regression was also observed in the study by Emerson and Morales (14), which used a low dosage of IFN- $\alpha 2 b$. The PFS in group A was longer than that in group B. This difference may have resulted from the benefit of tumor response, as PFS included two responses, PSA and tumor, in our present study. These results demonstrated that IFN- $\alpha 2 b$ may expand the antitumor activity of DXT chemotherapy. Such increased activity may result from several mechanisms, which may not be mutually exclusive. Firstly, IFN- $\alpha 2 b$ may be able to reduce the DXT resistance by downregulating $\mathrm{Bcl}-2$ as reported previously $(11,21)$. Overexpression of Bcl-2 is important in antitumor drug resistance, including hormonal and chemotherapy resistance found in CRPC $(22,23)$. Secondly, IFN- $\alpha 2 b$ may increase DXT sensitivity by upregulating the activity of p53 (12,24). Mutant p53 or the lack of functional p53 usually causes drug resistance, while restoring p53 function leads to regression of autochthonous lymphomas and sarcomas in mice without affecting normal tissues (9). In addition, IFN- $\alpha 2 b$ may synergize with DXT to promote apoptosis of tumor cells, the rapid growth of which depends on sustained angiogenesis (13).

Although the overall survival was longer in CRPC patients treated with DXT + IFN- $\alpha 2 b$, there was no statistically significant difference between the two groups. One reason for this finding may be due to the fact that the improved PSA and tumor responses are not necessarily transformed into a survival advantage. For example, a large-scale phase III clinical study was recently conducted on the basis of the rationale that targeting neovasculature and microtubules could enhance the clinical impact of DXT alone (25). However, despite the advantages of improved PSA response and delayed disease progression, the anti-angiogenic agent bevacizumab in combination with DXT did not significantly prolong survival compared with DXT alone (25). The small sample size and short follow-up time of the present study may be another reason for these findings.

From the viewpoint of safety, while the incidence of grade 3 to 4 toxicity was not statistically significant between the two groups, neutropenia was still frequently observed in group A. This side-effect may be due to suppression of the release of granulocytes by IFN- $\alpha 2 b$ in the bone marrow (26). This adverse event can often be safely and effectively controlled by administration of G-CSF. It should be noted that five patients with grade 3 to 4 neutropenia were poorly responsive to G-CSF; however, neutropenia could be attenuated by reducing the DXT dose, increasing the interval between doses and decreasing the number of chemotherapy cycles. Thus, careful follow-up is required. However, a few reports have shown that the toxicity of IFN- $\alpha 2 b$ is not well-tolerated in CRPC $(20,27)$. We hypothesize that the toxicities in the previous studies and the present study are different due to the following reasons. First, the IFN- $\alpha 2 b$ dosage was different. We employed a lower dose of IFN- $\alpha 2 b$ [3 vs. $6 \mathrm{mIU} / \mathrm{m}^{2}$ (20) or $\left.10 \mathrm{mIU} / \mathrm{m}^{2}(17)\right]$. The second reason is the differences in infusion time of IFN- $\alpha 2 b$. DXT-induced hematological toxicities most frequently occurred during the first 10 days of every cycle, particularly on days 5 and 7 (28). DXT combined with IFN- $\alpha 2$ b may increase the patient's adverse events during this period. Patients were administered in the third week of the cycle (days 16, 18 and 20) in the present study. However, IFN- $\alpha 2$ b was used on days 1 and 2 of each week in the trial by DiPaola et al (20). In addition, the patients had a better performance status prior to chemotherapy [ECOG $\leq 1$ vs. ECOG $\leq 2(17,19)]$ in the present study.

In conclusion, a low dosage of IFN- $\alpha 2 b$ may expand the effects of DXT chemotherapy with improvements in tumor response and PFS in patients with CRPC. The main side-effects were neutropenia, fever and general fatigue, which 
may be safely controlled by administration of G-CSF and symptomatic treatment. Further evaluation of a large number of patients with a longer follow-up period is required.

\section{Acknowledgements}

This study was supported by the National Natural Science Foundation of China (grant no. 30860281). The authors would like to thank Dr Jianjun Wu (Xi'an Jiaotong University) for comments on the study.

\section{References}

1. Feldman BJ and Feldman D: The development of androgen-independent prostate cancer. Nat Rev Cancer 1: 34-45, 2001.

2. Pienta KJ and Bradley D: Mechanisms underlying the development of androgen-independent prostate cancer. Clin Cancer Res 12: 1665-1671, 2006.

3. Tannock IF, de Wit R, Berry WR, et al: Docetaxel plus prednisone or mitoxantrone plus prednisone for advanced prostate cancer. N Engl J Med 351: 1502-1512, 2004.

4. Berthold DR, Pond GR, Soban F, de Wit R, Eisenberger M and Tannock IF: Docetaxel plus prednisone or mitoxantrone plus prednisone for advanced prostate cancer: updated survival in the TAX 327 study. J Clin Oncol 26: 242-245, 2008.

5. Makarovskiy AN, Siryaporn E, Hixson DC and Akerley W: Survival of docetaxel-resistant prostate cancer cells in vitro depends on phenotype alterations and continuity of drug exposure. Cell Mol Life Sci 59: 1198-1211, 2002.

6. McDonnell TJ, Troncoso P, Brisbay SM, et al: Expression of the protooncogene bcl-2 in the prostate and its association with emergence of androgen-independent prostate cancer. Cancer Res 52: 6940-6944, 1992.

7. Banerjee PP, Banerjee S and Brown TR: Bcl-2 protein expression correlates with cell survival and androgen independence in rat prostatic lobes. Endocrinology 143: 1825-1832, 2002.

8. Ventura A, Kirsch DG, McLaughlin ME, et al: Restoration of p53 function leads to tumour regression in vivo. Nature 445 . 661-665, 2007.

9. Leprince D, Crepieux P, Laudet V, Flourens A and Stehelin D: A new mechanism of oncogenic activation: E26 retroviral v-ets oncogene has inverted the C-terminal end of the transcription factor c-ets-1. Virology 194: 855-857, 1993.

10. Liu C, Zhu Y, Lou W, et al: Functional p53 determines docetaxel sensitivity in prostate cancer cells. Prostate 73: 418-427, 2013.

11. Panaretakis T, Pokrovskaja K, Shoshan MC and Grander D: Interferon-alpha-induced apoptosis in U266 cells is associated with activation of the proapoptotic Bcl-2 family members Bak and Bax. Oncogene 22: 4543-4556, 2003.

12. Davol PA, Goulette FA, Frackelton AR Jr and Darnowski JW: Modulation of p53 expression by human recombinant interferon-alpha2a correlates with abrogation of cisplatin resistance in a human melanoma cell line. Cancer Res 56 2522-2526, 1996.
13. Huang SF, Kim SJ, Lee AT, et al: Inhibition of growth and metastasis of orthotopic human prostate cancer in athymic mice by combination therapy with pegylated interferon-alpha-2b and docetaxel. Cancer Res 62: 5720-5726, 2002

14. Emerson L and Morales A: Intralesional recombinant alpha-interferon for localized prostate cancer: a pilot study with follow-up of >10 years. BJU Int 104: 1068-1070, 2009.

15. Shinohara N, Abe T, Sazawa A, et al: Interferon- $\alpha$-based immunotherapy in metastatic renal cell carcinoma patients with the primary tumor in situ. Jpn J Clin Oncol 42: 113-119, 2012

16. Mocellin S, Pasquali S, Rossi CR and Nitti D: Interferon alpha adjuvant therapy in patients with high-risk melanoma: a systematic review and meta-analysis. J Natl Cancer Inst 102: 493-501, 2010.

17. van Haelst-Pisani CM, Richardson RL, Su J, et al: A phase II study of recombinant human alpha-interferon in advanced hormone-refractory prostate cancer. Cancer 70: 2310-2312, 1992.

18. Bulbul MA,Huben RP and Murphy GP: Interferon-beta treatment of metastatic prostate cancer. J Surg Oncol 33: 231-233, 1986

19. Padhani AR and Ollivier L: The RECIST (Response Evaluation Criteria in Solid Tumors) criteria: implications for diagnostic radiologists. Br J Radiol 74: 983-986, 2001.

20. DiPaola RS, Chen YH, Stein M, et al: A randomized phase II trial of mitoxantrone, estramustine and vinorelbine or bcl-2 modulation with 13 -cis retinoic acid, interferon and paclitaxel in patients with metastatic castrate-resistant prostate cancer: ECOG 3899. J Transl Med 8: 20, 2010.

21. Anatol P, Danuta P, Janusz D and Bozena P: Expression of bcl-2 protein in chronic hepatitis $\mathrm{C}$ : effect of interferon alpha $2 \mathrm{~b}$ with ribavirin therapy. World J Gastroenterol 11: 2949-2952, 2005.

22. Amato RJ and Mohammad T: Interferon-alpha plus capecitabine and thalidomide in patients with metastatic renal cell cancer. $\mathrm{J}$ Exp Ther Oncol 7: 41-47, 2008.

23. Rosevear HM, Lightfoot AJ, Nepple KG and O'Donnell MA: Usefulness of the Spanish Urological Club for Oncological Treatment scoring model to predict nonmuscle invasive bladder cancer recurrence in patients treated with intravesical bacillus Calmette-Guérin plus interferon- $\alpha$. J Urol 185: 67-71, 2011.

24. Panasiuk A, Prokopowicz D and Dzieciol J: p53 protein expression in chronic hepatitis $\mathrm{C}$; effect of interferon alpha $2 \mathrm{~b}$ therapy. Hepatogastroenterology 52: 1176-1179, 2005.

25. Kelly WK, Halabi S,Carducci M, et al: Randomized, double-blind, placebo-controlled phase III trial comparing docetaxel and prednisone with or without bevacizumab in men with metastatic castration-resistant prostate cancer: CALGB 90401. J Clin Oncol 30: 1534-1540, 2012.

26. Koirala J, Gandotra SD, Rao S, et al: Granulocyte colony-stimulating factor dosing in pegylated interferon alpha-induced neutropenia and its impact on outcome of anti-HCV therapy. J Viral Hepat 14: 782-787, 2007.

27. Chang AY, Fisher HA, Spiers AS and Boros L: Toxicities of human recombinant interferon-alpha 2 in patients with advanced prostate carcinoma. J Interferon Res 6: 713-715, 1986.

28. ten Tije AJ, Verweij J, Carducci MA, et al: Prospective evaluation of the pharmacokinetics and toxicity profile of docetaxel in the elderly. J Clin Oncol 23: 1070-1077, 2005. 